\title{
SOCIAL CHANGE, MIGRATION AND PREGNANCY INTERVALS
}

\author{
I. POOL*, J. E. SCEATS $\dagger$, A. HOOPER $\ddagger$, J. HUNTSMAN $\ddagger$, \\ E. PLUMMER $\ddagger$ AND I. PRIOR§
}

\begin{abstract}
*Population Studies Centre, University of Waikato, Hamilton, $\uparrow$ Waikato Hospital, Hamilton, $\ddagger$ Department of Anthropology, University of Auckland, and $\S$ Epidemiology Unit, Wellington Hospital, New Zealand
\end{abstract}

\begin{abstract}
Summary. Maternity histories from residents of a Pacific Island society, Tokelau, and migrants to New Zealand, are analysed using life table techniques. Inter-cohort differentials in patterns of family formation were found in the total Tokelau-origin population. The process of accelerated timing and spacing of pregnancies was more pronounced among migrants who tended to marry later, be pregnant at marriage, have shorter inter-pregnancy intervals at lower parities and to show evidence of family limitation occurring at higher parities. These results point to the significance of changing patterns of social control on strategies of family building.
\end{abstract}

\section{Introduction}

Migration is one of the more radical forms of social change; whether international or internal, it has a marked effect on both individuals and societies. Studies of the relationship between migration and fertility often produce contradictory results, in part because of methodological problems rather than substantive issues (Zarate \& Zarate, 1975). For example, in Thailand, Goldstein (1978) found differentials (in varying directions) by duration of residence, and types of origin and destination, but with a marked and over-riding urban-rural difference. Again, a study of Samoan migration and fertility demonstrated that migrants to 'less traditional communities' have lower fertility than non-migrants or migrants to 'traditional communities' (Harbison \& Weishaar, 1981).

In order to reconcile conflicting evidence relating to fertility differentials over time, a three stage model, in which the stages need not be mutually exclusive for all groups, was proposed for Africa (Coulibaly \& Pool, 1975). At stage one selective cyclical migration, long-term, of the young and single may produce lower urban than rural fertility. The effects of short-term migration on fertility at the area of origin was documented for a Swiss population (Van de Walle, 1975), while a number of attempts have been made to model the effects of cyclical migrations on fertility (e.g. Potter \& Kobrin, 1982). With a second stage of family migration 
I. Pool et al.

urban fertility might well be higher than rural. A third stage may involve the adoption of host-community reproductive norms and attitudes favouring contraception, initially in terms of its role in limitation.

Studies on migration and fertility must rely either on conventional period indices or on non-conventional measures obtained by indirect estimation (e.g. Harbison \& Weishaar, 1981). From such data only limited analyses of dynamics can be made, while changes in tempo may be exaggerated (e.g. where it accelerates because of the shortening of birth intervals). Moreover, many studies have had to rely on macro-level cumulative fertility data (e.g. Goldstein, 1978). Although these relate to age cohorts, they may obscure differentials in underlying dynamics (e.g. differences in age at marriage and in the timing and spacing of births).

The present paper employs life-table techniques to analyse data for a Pacific island Polynesian society, Tokelau, undergoing rapid migration to a developed country. Two previous studies of this population (Hooper \& Huntsman, 1973; Stanhope \& Prior, 1977) have dealt briefly with fertility, both using cumulative data. In the earlier study, a descriptive demographic history and social and cultural factors affecting fertility in the home atoll communities were discussed (Hooper \& Huntsman, 1973). The later study compared women who stayed in the atolls with those who later moved to New Zealand, but 'no significant differences emerged between non-migrant and pre-migrant females'. More importantly, the cumulative fertility rates implied that the quantum of fertility had remained consistently high (around 6.5 births per woman) for a number of generations (Hooper \& Huntsman, 1973).

\section{Data and methods}

The present paper makes use of further Tokelau data and different methods to investigate cohort differentials for both the residents of the Tokelau homeland and the migrants resident in New Zealand. The data were collected using conventional anthropological techniques of informal interview, supplemented by the use of other sources, in order to construct maternity histories. The material was then coded so that quantitative methods of analysis could be employed. A life-table approach drawing upon the coded maternity histories makes it possible to compare cohorts reproducing at different periods and thus to analyse changes over time in family formation strategies.

This method, drawing here on a technique first developed by one of the co-authors (see below), has been explored by others using a somewhat different approach (Hobcraft \& Rodriguez, 1980; Nijhuis, 1983). Because of the way in which the Tokelau data were collected, as well as the availability of closely related data files, the results of the present study may permit not only further exploration of the demographic issues, but also the investigation of associated social anthropological and epidemiological issues. From a demographic standpoint such a study fits in well with a growing interest in the value of micro-level studies, particularly as these add to knowledge of an interpretative nature.

The data were collected as part of a long-term, multidisciplinary collaborative study of changing health status among Tokelauans, both in their home atolls and as 
migrants to New Zealand. The Tokelau Island Migrant Study was formally established in 1970 , but had been preceded by separate projects initiated by the ethnographers and epidemiologists involved beginning in 1967. Materials collected in the earlier studies formed the basis for later close collaboration during field research in the atolls in 1971 and 1976, and in New Zealand in 1972 and 1977. The data used relate to the status of respondents in 1976 or 1977.

Migration of Tokelauans to New Zealand began in the early 1960s, and was encouraged by the New Zealand government in the middle and later 1960s. The atoll population, which reached a peak at about 1900 in the mid-1960s, stabilized at about 1600 in the 1970s. At the same time, however, the migrant population in New Zealand increased dramatically, from perhaps 30 persons in 1962 , to some 1800 in 1972 and to about 3000 in 1982 . The New Zealand population was substantially augmented by Tokelauans who migrated from Samoa, many of whom had never lived in the atolls, and so does not represent only former Tokelau residents and their New Zealand-born progeny. None the less, the growth of the migrant population is striking.

Tokelau has changed greatly in the past decade, but the contrast with New Zealand urban and semi-urban areas to which the migrants came is extreme: from tropical atolls with limited resources (e.g. no natural soil, no running water), to a relatively vast and rich land of temperate climate; from a primarily subsistence economy based on fish and coconut, to a wage and market economy; from small, close-knit, homogeneous and firmly controlled village communities to large, heterogeneous, loosely organized cities and suburbs. Most Tokelauans in New Zealand maintain distinctive Tokelau aspects of their life style. But a good deal of interchange between the two Tokelau populations helps to account for both the changes in the atolls and the maintenance of distinct Tokelau communities in New Zealand. The long-term design of the Tokelau Island Migrant Study has allowed this to be documented.

The techniques of life-table analysis used here were first developed by Sceats (Sceats-Pool, 1978) and were later applied to data drawn from a sample survey in the Manawatu region of New Zealand (Sceats, 1981). They permit the detailed study of pregnancy intervals (in the present study pregnancies rather than births are used) and also serve to eliminate biases which result from truncation. This bias is introduced by the intervention of the data collection or observation process, which serves to exclude those respondents who have not yet reached a stage in their life cycle when they may or may not have achieved the event in question. However, even with the application of life-table techniques, the truncation biases are not entirely eliminated (Sceats, 1981; Hobcraft \& Rodriguez, 1980; Nijhuis, 1983). For this reason, values for older ages and higher parities will not be presented for younger cohorts.

Two sets of results are presented here. First, there is the probability of achieving a given parity progression over a specific duration, measured here either in terms of quartiles, or achievement of parity $i$, by 24 and 30 months after parity $i-1$. This constitutes a measure of spacing. Secondly, the results are presented in terms of the probability of achieving a given parity by a particular age. This constitutes a measure of the timing of pregnancies. In both cases the probabilities are 
conditional, i.e. the probability that a respondent who has already achieved parity $i$ will go on to achieve parity $i+1$.

One further analytical problem must be mentioned. Because cell sizes are small some of the results are subject to problems of sampling error. This cannot be estimated because the measure of central tendency which is appropriate to this form of life-table is the median. Consequently, standard measures of sampling error are not applicable. Because of the possibility of sampling errors, results are inferred from systematic patterns rather than unique apparently significant results. These systematic patterns are all intuitively reasonable, suggesting that the technique is relatively robust and also that they are not a product of culturally-induced respondent bias.

\section{Results}

\section{Cohort changes}

Results related to spacing for the different birth cohorts are presented in Table 1 , showing the upper and lower quartiles and medians (in months) by which particular parity progressions are achieved between marriage and pregnancy 1 , pregnancy 1 and pregnancy 2 , and so on. For the total population, the median duration of achieving pregnancy 1 is at time of marriage, and even those women who are slow in conceiving have done so by the 5th month. From then on, the lower quartiles and medians centre around $1 \frac{1}{2}-2$ years for the majority of parities, but become rather longer (from just under 2 years to almost $2 \frac{1}{2}$ years) at the highest parity for which it is possible to carry out computations, given the problems of sampling errors and truncation bias. The upper quartiles show greater variability, but with a more or less systematic shift towards longer periods at higher parities.

There is a clear indication of an inter-cohort transition towards shorter spacing, most notably in the interval between marriage and pregnancy 1. This effect characterizes the lowest quartile and, to a certain degree, the median for each of the parity progressions. For the upper quartile of higher parities, however, the variations appear to present no specific pattern. (The changes by birth cohort (Tables 1-3) are influenced by migration, which will be discussed later.)

In Table 2 birth cohorts for the total survey are analysed in terms of the cumulative probability of reaching a particular parity by a given age. These results support those drawn from period measures and reviewed. Across the total sample, the probability of ever conceiving is $90 \%$ (i.e. the progression from marriage to pregnancy 1 before age 50), but the great majority of women will have completed this first progression before age 25 , and almost all who ever make the progression will have done so by age 30 with few differences between cohorts. Not surprisingly, as the parities increase the proportion achieving that parity by a given age (or ever) diminishes. Thus, only $47 \%$ will have achieved parity 4 by age 30 , with minimal inter-cohort differences. These quantum aspects of parity progression must be kept in mind when later analyses are presented.

A major difference between cohorts, particularly for the transition from marriage to parity 1 , is obscured in this overall picture. A lower proportion of the 
Social change, migration and pregnancy intervals

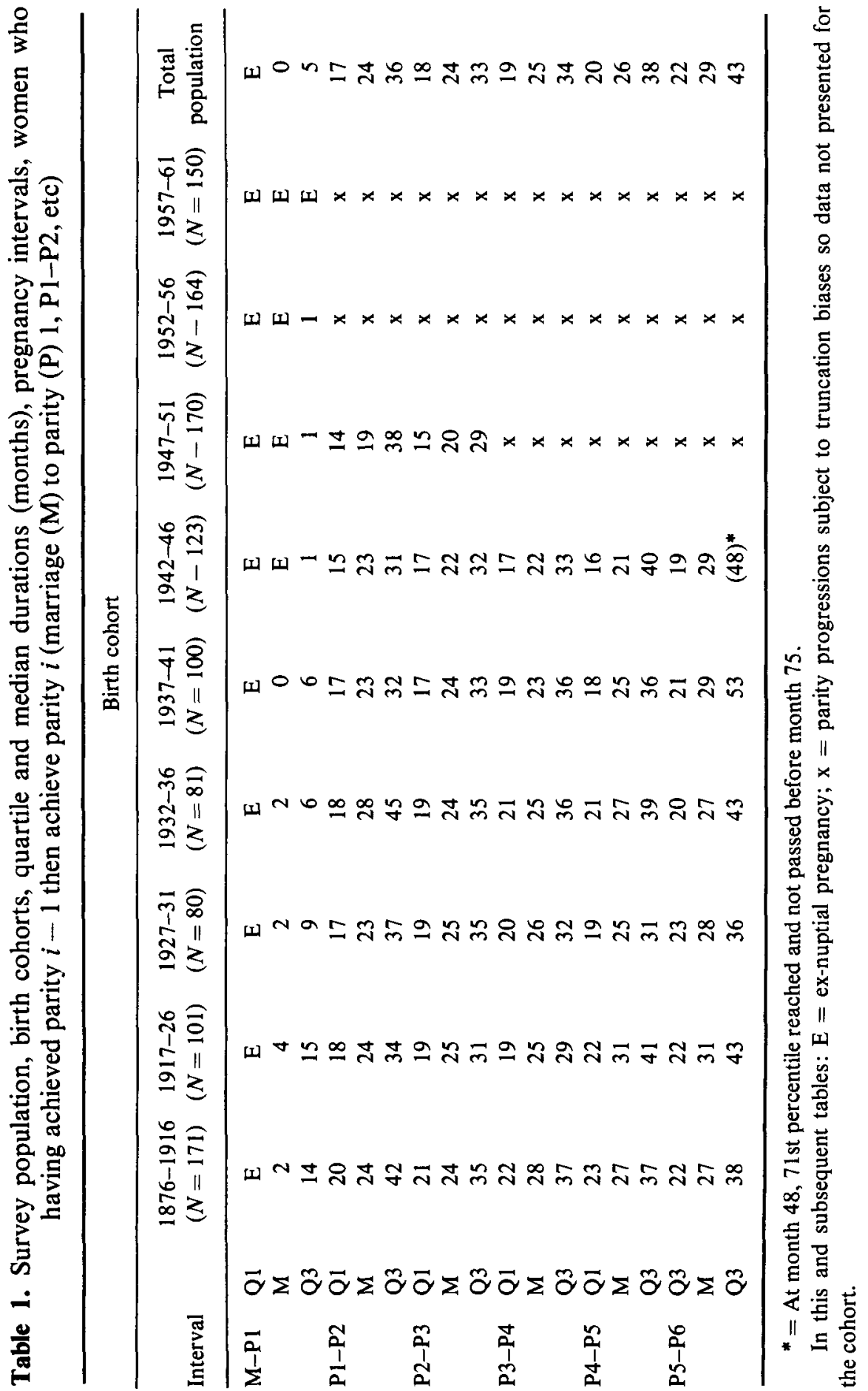




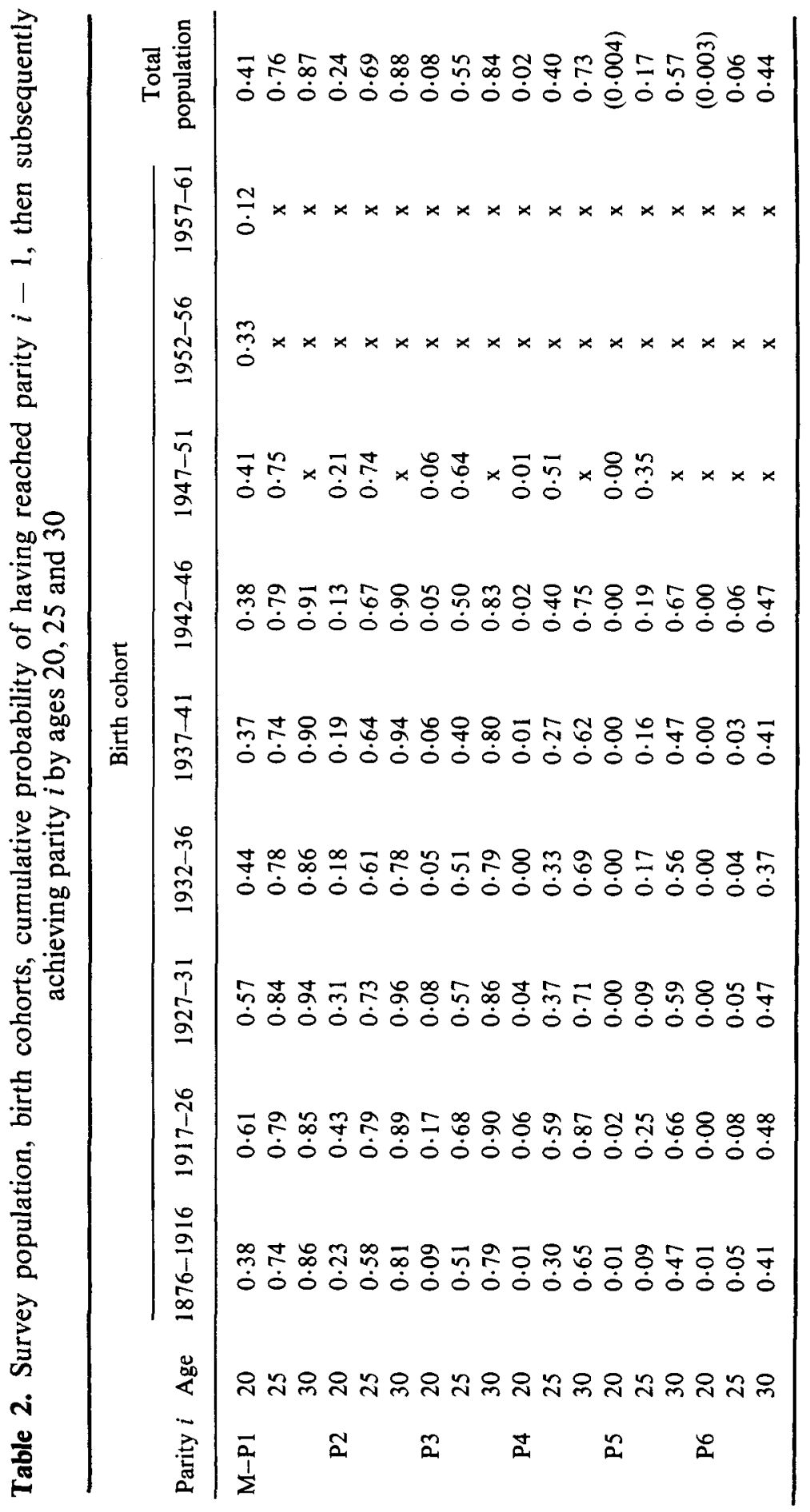


Social change, migration and pregnancy intervals

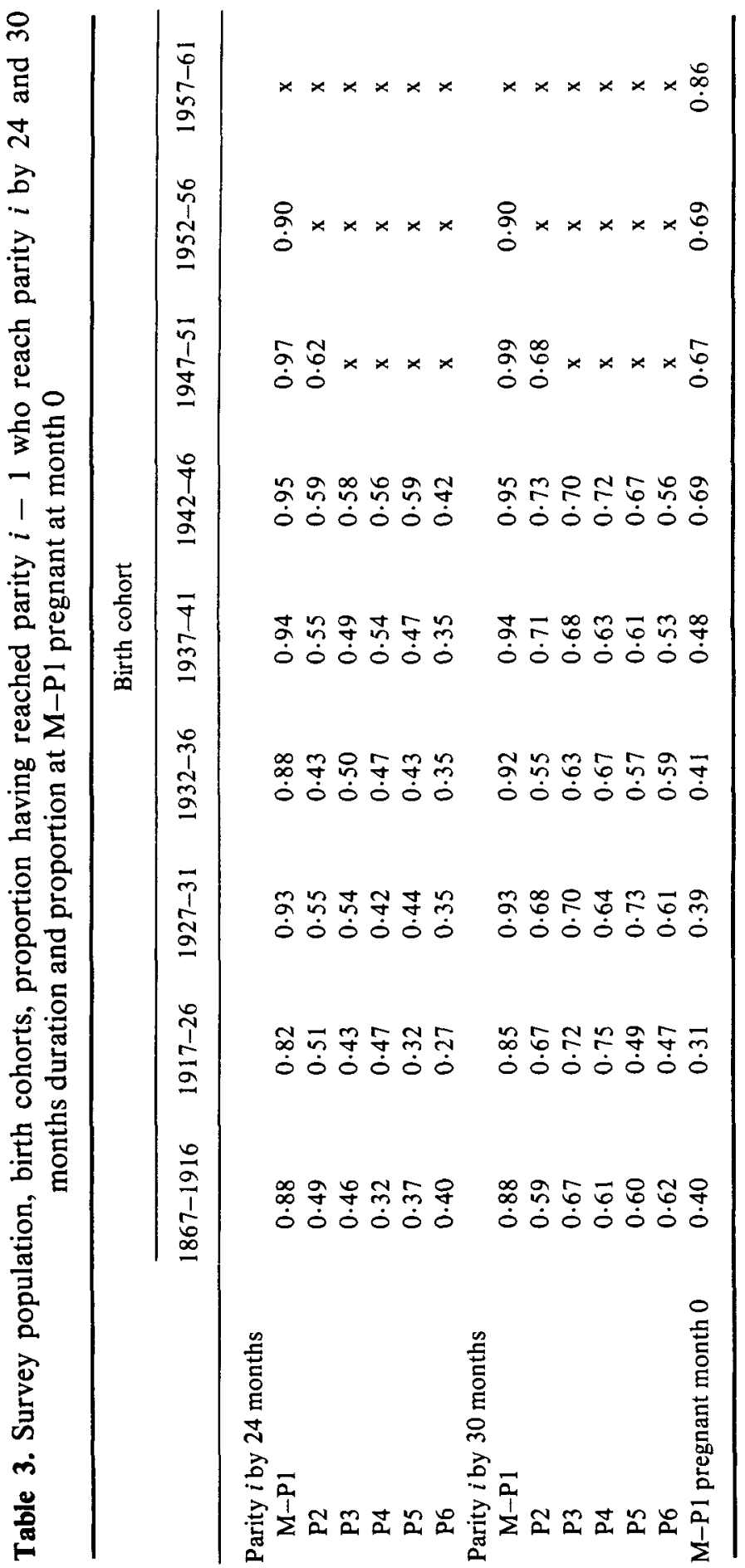


younger cohorts have achieved this progression by age 20 than is true for the older cohorts. Nevertheless, by age 25 the cohorts are very homogeneous in terms of first parity progression, some $75 \%$ having achieved it, and similar degrees of homogeneity exist at age 30 .

The proportion of respondents who were pregnant at the time of marriage is given in Table 3. It shows a systematic progression from the older to younger cohorts of an increasing proportion of pre-nuptial pregnancies. The high proportions of the youngest cohorts must be treated, however, with caution, particularly for the cohort born 1957-61, because there will be a truncation bias towards those women who make the transition at younger ages. Nevertheless, overall the result is strong for two reasons: (1) there is such a systematic trend in the older cohorts; and (2) there is a significant $(0.01$ level) inverse correlation (Spearman's $\rho=-0.88$ ) between the proportion who were pregnant at the time of marriage and the proportion who had made this transition at age 20 (Table 2). For older cohorts at age 20 , higher proportions had already conceived, indicating that older cohorts married younger and were pregnant within marriage at 20 , whereas the younger cohorts married later, but did so following ex-nuptial conceptions.

\section{Differences between Tokelau residents and New Zealand residents}

The possible effects of migration are examined by comparing the atoll and New Zealand populations in terms of spacing (Table 4) and timing (Table 5).

Table 4. Sub-populations, ${ }^{*}$ quartile and median durations (months), pregnancy intervals, women who having achieved parity $i-1$ achieve parity $i$

\begin{tabular}{llcc}
\hline Interval & & Tokelau $(N=648)$ & New Zealand $(N=490)$ \\
\hline M-P1 & Q1 & E & E \\
& M & 2 & $\mathrm{E}$ \\
& Q3 & 8 & 2 \\
P1-P2 & Q1 & 19 & 15 \\
& M & 24 & 22 \\
& Q3 & 37 & 36 \\
P2-P3 & Q1 & 19 & 16 \\
& M & 24 & 23 \\
& Q3 & 32 & 36 \\
P3-P4 & Q1 & 21 & 17 \\
& M & 26 & 22 \\
& Q3 & 34 & 35 \\
P4-P5 & Q1 & 21 & 18 \\
& M & 26 & 26 \\
& Q3 & 36 & 47 \\
P5-P6 & Q1 & 22 & 20 \\
& M & 28 & 30 \\
& Q3 & 40 & 48 \\
\hline
\end{tabular}

* In Tables 4-9: Tokelau residents and New Zealand residents. 
Table 5. Sub-populations, cumulative probability of having reached parity $i-1$, then achieving parity $i$ by ages 20,25 and 30

\begin{tabular}{cccc}
\hline Parity $i$ & Age & Tokelau & New Zealand \\
\hline M-P1 & 20 & 0.44 & 0.38 \\
& 25 & 0.75 & 0.78 \\
P2 & 30 & 0.86 & 0.89 \\
& 20 & 0.26 & 0.21 \\
& 25 & 0.71 & 0.65 \\
P3 & 30 & 0.87 & 0.91 \\
& 20 & 0.09 & 0.07 \\
& 25 & 0.60 & 0.47 \\
P4 & 30 & 0.85 & 0.81 \\
& 20 & 0.02 & 0.03 \\
& 25 & 0.41 & 0.38 \\
P5 & 30 & 0.77 & 0.65 \\
& 20 & 0.01 & 0.00 \\
& 25 & 0.16 & 0.20 \\
P6 & 30 & 0.62 & 0.46 \\
& 20 & 0.00 & 0.00 \\
& 25 & 0.06 & 0.06 \\
& 30 & 0.48 & 0.35 \\
\hline
\end{tabular}

The data on spacing suggest that the reduction of durations, which had been proceeding cohort by cohort, was accelerated by the process of migration, for the New Zealand residents have spacing patterns which resemble those of the younger cohorts for the entire population. For all Tokelauans conception durations are short, even for quartile 3 after marriage, but for the New Zealand residents the zero parity first quartile and median values are even lower. These results confirm the comments of Stanhope \& Prior (1977) based on cumulative rates.

In the upper quartile, however, a reverse pattern starts to emerge among the New Zealand resident women around the progression from pregnancy 2 to pregnancy 3 . This shift eventually becomes the dominant pattern, firstly at the upper quartile, and by parity progression 5-6 at the median as well. This evidence of prolonged spacing may indicate the incipient commencement of family planning for the purposes of limitation among women reaching higher parities in New Zealand. This result might well have been stronger had the truncation biases been totally eliminated, for they have the effect of exaggerating downwards these durations.

Table 5 relates to the cumulative probability that women at a given age who have reached parity $i$ will go on to $i+1$. Again these data point to an element of change in patterns of social control. First, the New Zealand resident women marry later (confirming the results of Stanhope \& Prior, 1977), and the progressions through to parities 1 and 2 are later than in Tokelau (i.e. lower proportions at age 
25). However, the probability of achieving pregnancies by age 30 are higher for New Zealand women than for Tokelau women, demonstrating an acceleration in the tempo of family building once it has begun. This result corresponds to recent data on Samoan fertility (Harbison \& Weishaar, 1981). At all parities, after the initial delay, timing is shorter for the New Zealand sub-population, reinforcing the observations on spacing (Table 4). By contrast, although the lower parity women in New Zealand are more likely to have achieved their pregnancies by age 30 than are those in Tokelau, at higher parities the reverse is systematically true.

It is possible that these apparent results of migration may be more an artefact of cohort composition. One would expect New Zealand women to be overrepresented among the younger cohorts (a control for this could not be made by Stanhope \& Prior, 1977). In order to control for this in the present study, data on the two domiciles were divided into cohorts with wider spans than those used for the entire survey population (Tables 6-9). Because sub-populations are small in size these results are even more subject to sampling error, and those for the youngest population are clearly affected by truncation bias.

Table 6. Sub-populations, birth cohorts, quartile and median durations (months) pregnancy intervals, women having achieved parity $i-1$ achieve parity $i$

\begin{tabular}{|c|c|c|c|c|c|c|c|}
\hline \multirow[b]{3}{*}{ Interval } & & \multicolumn{6}{|c|}{ Birth cohort } \\
\hline & & \multicolumn{2}{|c|}{$1927-41$} & \multicolumn{2}{|c|}{$1942-51$} & \multicolumn{2}{|c|}{$1952-61$} \\
\hline & & $\begin{array}{l}\text { Tokelau } \\
(N=142)\end{array}$ & $\begin{array}{l}\text { New Zealand } \\
\quad(N=99)\end{array}$ & $\begin{array}{c}\text { Tokelau } \\
(N=96)\end{array}$ & $\begin{array}{c}\text { New Zealand } \\
(N=197)\end{array}$ & $\begin{array}{c}\text { Tokelau } \\
(N=131)\end{array}$ & $\begin{array}{c}\text { New Zealand } \\
(N=181)\end{array}$ \\
\hline \multirow[t]{3}{*}{$\mathbf{M}-\mathbf{P} \mathbf{1}$} & Q1 & $\mathrm{E}$ & $\mathrm{E}$ & $\mathrm{E}$ & $\mathrm{E}$ & $\mathrm{E}$ & $\mathrm{E}$ \\
\hline & $\mathbf{M}$ & 2 & 0 & $\mathrm{E}$ & $\mathrm{E}$ & E & $\mathrm{E}$ \\
\hline & Q3 & 7 & 6 & 3 & 1 & 0 & 2 \\
\hline \multirow[t]{3}{*}{$\mathrm{P} 1-\mathrm{P} 2$} & Q1 & 18 & 17 & 18 & 14 & 22 & 19 \\
\hline & $\mathbf{M}$ & 23 & 25 & 25 & 19 & 26 & 31 \\
\hline & $Q^{3}$ & 33 & 37 & 35 & 30 & 29 & 50 \\
\hline \multirow[t]{3}{*}{ P2-P3 } & Q1 & 19 & 17 & 18 & 16 & $x$ & $\mathbf{x}$ \\
\hline & $\mathbf{M}$ & 24 & 24 & 21 & 21 & $\mathbf{x}$ & $\mathrm{x}$ \\
\hline & Q3 & 32 & 38 & 25 & 33 & $\mathrm{x}$ & $x$ \\
\hline \multirow[t]{3}{*}{ P3-P4 } & Q1 & 21 & 19 & 19 & 16 & $\mathbf{x}$ & $\mathbf{x}$ \\
\hline & $\mathbf{M}$ & 25 & 23 & 23 & 21 & $\mathbf{x}$ & $\mathrm{x}$ \\
\hline & Q3 & 34 & 33 & 28 & 37 & $\mathbf{x}$ & $\mathbf{x}$ \\
\hline \multirow[t]{3}{*}{ P4-P5 } & Q1 & 20 & 19 & 17 & 16 & $\mathrm{x}$ & $x$ \\
\hline & $\mathbf{M}$ & 25 & 25 & 21 & 26 & $\mathrm{x}$ & $x$ \\
\hline & Q3 & 33 & 44 & 25 & $*$ & $\mathbf{x}$ & $x$ \\
\hline \multirow[t]{3}{*}{ P5-P6 } & Q1 & 21 & 22 & 21 & 17 & $\mathbf{x}$ & $\mathrm{x}$ \\
\hline & $\mathbf{M}$ & 27 & 30 & 25 & 30 & $\mathrm{x}$ & $\mathbf{x}$ \\
\hline & Q3 & 38 & 47 & 34 & $\dagger$ & $\mathrm{x}$ & $\mathrm{x}$ \\
\hline
\end{tabular}

* 0.71 at month 49 , and no higher.

$\dagger 0.62$ at month 49 , and no higher. 
In spite of these statistical problems, systematic results appear. The quartile and median duration data (Table 6) demonstrate very broadly the effects noted for each cohort. In general, for the two older cohorts the New Zealand women have shorter intervals between their earlier pregnancies than do the Tokelau women, but longer intervals between their later ones. With the exception of the progression from pregnancy 3 to 4 for the 1927-41 cohort, the New Zealand upper quartile values are higher than the Tokelau, probably indicating an incipient trend towards family limitation.

The 1942-51 cohort shows a clear difference. On the one hand, among the Tokelau residents there are fairly even spacing patterns with gradually increasing durations at higher parities, as would be expected for biosocial reasons. On the other hand, rapid spacing at low parities and for the first quartiles thereafter occurs among the New Zealand women, but with extended durations at high parity medians and for the upper quartiles onwards from parity progression 2-3. Because of sampling errors and truncation biases it is difficult to interpret the upper quartile values for the highest parities for New Zealand women for this cohort.

The youngest cohort supports this general pattern, but again it may be difficult to interpret because of truncation biases. At face value it indicates a shift towards fertility regulation, and the possible adoption of spacing strategies between parity 1 and parity 2 . This would be a very natural progression from the patterns of pregnancy interval dynamics demonstrated for the cohort of 1942-51. (The possibility of a pattern of an ex-nuptial pregnancy followed some years later by marriage and nuptial pregnancy should not be dismissed.)

Timing patterns, by cohort and domicile (Table 7), permit a finer analysis to be made of the gross differences between Tokelau and New Zealand populations in regard to spacing. The 1927-41 cohort demonstrates quite dramatically the effects of migration. The New Zealand resident women, who generally would have been migrating during their reproductive span, have markedly lower levels of achievement for given parities by ages 20,25 and 30 than do their Tokelau counterparts. This could be for two reasons: (1) selectivity, e.g. those who wished to migrate did so as single women, and thus delayed getting married (cf. Stanhope \& Prior, 1977; Harbison \& Weishaar, 1981), or (2) for those already in conjugal unions, separation from spouses during the migration process. In the light of the history of Tokelau migration, the second reason seems more important. A number of single women were 'assisted' to migrate between 1963 and 1966, but few of them would have been born before 1942. In the period 1963-66 and for several years before, there was a spontaneous chain-migration of families, affecting women of the 1927-41 cohort. From 1967 on, under the sponsored 'resettlement scheme', families were assisted to migrate as units, but since young families were preferred, many (but not all) of the women would have been of the subsequent cohort.

The 1942-51 cohort predominantly represents the young single women plus passive migrant children of the earlier or more mature migrant families. Their timing demonstrates clearly the contradictory patterns for the New Zealand resident sub-population. From 20 years it is rapid at earlier parities, after an initial, relative, delay. At later parities timing becomes slower and slower so that they fall behind the tempo achieved by Tokelau residents: Table 8 summarizes the 
Table 7. Sub-populations, birth cohorts, cumulative probability of having reached parity $i-1$, then achieving parity $i$ by ages 20,25 and 30

\begin{tabular}{|c|c|c|c|c|c|c|c|}
\hline \multirow[b]{3}{*}{ Parity $i$} & \multirow[b]{3}{*}{ Age } & \multicolumn{6}{|c|}{ Birth cohort } \\
\hline & & \multicolumn{2}{|c|}{$1927-41$} & \multicolumn{2}{|c|}{$1942-51$} & \multicolumn{2}{|c|}{$1952-61$} \\
\hline & & Tokelau & New Zealand & Tokelau & New Zealand & Tokelau & New Zealand \\
\hline \multirow[t]{3}{*}{ M-P1 } & 20 & 0.55 & 0.28 & 0.37 & 0.41 & 0.41 & 0.40 \\
\hline & 25 & 0.81 & 0.75 & 0.71 & 0.80 & 0.72 & 0.65 \\
\hline & 30 & 0.90 & 0.91 & 0.85 & 0.91 & $x$ & $\mathbf{x}$ \\
\hline \multirow[t]{3}{*}{ P2 } & 20 & 0.27 & 0.15 & $0 \cdot 13$ & 0.19 & $\mathrm{x}$ & $\mathbf{x}$ \\
\hline & 25 & 0.75 & 0.51 & 0.73 & 0.69 & $\mathrm{x}$ & $\mathbf{x}$ \\
\hline & 30 & 0.91 & 0.87 & 0.87 & 0.91 & $\mathbf{x}$ & $\mathbf{x}$ \\
\hline \multirow[t]{3}{*}{ P3 } & 20 & 0.08 & 0.05 & 0.05 & 0.06 & $\mathrm{x}$ & $\mathbf{x}$ \\
\hline & 25 & 0.63 & 0.27 & 0.58 & 0.57 & $\mathrm{x}$ & $\mathbf{x}$ \\
\hline & 30 & 0.87 & 0.73 & 0.89 & 0.84 & $x$ & $\mathbf{x}$ \\
\hline \multirow[t]{3}{*}{ P4 } & 20 & 0.02 & 0.02 & 0.00 & 0.03 & $\mathrm{x}$ & $\mathrm{x}$ \\
\hline & 25 & 0.38 & 0.22 & 0.46 & 0.45 & $\mathrm{x}$ & $x$ \\
\hline & 30 & 0.78 & 0.49 & 0.82 & 0.76 & $\mathbf{x}$ & $\mathrm{x}$ \\
\hline \multirow[t]{3}{*}{ P5 } & 20 & 0.00 & 0.00 & 0.00 & 0.03 & $\mathrm{x}$ & $\mathrm{x}$ \\
\hline & 25 & $0 \cdot 16$ & $0 \cdot 10$ & $0 \cdot 16$ & 0.45 & $\mathrm{x}$ & $\mathbf{x}$ \\
\hline & 30 & 0.65 & 0.33 & 0.81 & 0.76 & $\mathrm{x}$ & $\mathbf{x}$ \\
\hline \multirow[t]{3}{*}{ P6 } & 20 & 0.00 & 0.00 & 0.00 & 0.00 & $\mathrm{x}$ & $\mathrm{x}$ \\
\hline & 25 & 0.05 & 0.03 & 0.07 & 0.09 & $\mathrm{x}$ & $\mathbf{x}$ \\
\hline & 30 & 0.52 & 0.25 & 0.57 & 0.48 & $\mathrm{x}$ & $x$ \\
\hline
\end{tabular}

Table 8. Sub-populations, cohort of 1942-51, cumulative probability of achieving parities 3 and 5 and of progressing from parity 3 to parity 5 by age 30

\begin{tabular}{lcc}
\hline By age 30 & Tokelau & New Zealand \\
\hline P3 & 0.66 & 0.70 \\
P5 & 0.44 & 0.31 \\
P3 to P5 & 0.59 & 0.38 \\
\hline
\end{tabular}

cumulative probability of achieving parities 3 and 6 by the age 30 . There is a crossover: a higher proportion of the New Zealand women had achieved parity 3 by age 30 , whereas a lower proportion had reached parity 5 by the same age. The difference in the cumulative probability of achieving the early parities by age 30 is not very great. By contrast, the cumulative probability of moving from parity 3 through to achievement of parity 5 is markedly different (Table 8). 
Table 9. Sub-populations, birth cohorts, proportion having reached parity $i-1$ who reach parity $i$ by 24 to 30 months duration, proportion at M-P1 pregnant at month 0

\begin{tabular}{|c|c|c|c|c|c|c|}
\hline & \multicolumn{6}{|c|}{ Birth cohort } \\
\hline & \multicolumn{2}{|c|}{$1927-41$} & \multicolumn{2}{|c|}{$1942-51$} & \multicolumn{2}{|c|}{$1952-61$} \\
\hline & Tokelau & New Zealand & Tokelau & New Zealand & Tokelau & New Zealand \\
\hline \multicolumn{7}{|c|}{ Parity $i$ by 24 months } \\
\hline $\mathbf{M}-\mathbf{P} 1$ & 0.92 & 0.92 & 0.95 & 0.95 & $\mathrm{x}$ & $\mathbf{x}$ \\
\hline P2 & 0.53 & 0.48 & 0.48 & 0.66 & $\mathbf{x}$ & $\mathbf{x}$ \\
\hline P3 & 0.51 & 0.51 & 0.68 & 0.60 & $\mathbf{x}$ & $\mathrm{x}$ \\
\hline P4 & 0.44 & 0.54 & 0.63 & 0.57 & $\mathbf{x}$ & $\mathrm{x}$ \\
\hline P5 & 0.45 & 0.46 & 0.69 & 0.49 & $\mathbf{x}$ & $\mathbf{x}$ \\
\hline P6 & 0.39 & 0.29 & 0.41 & 0.43 & $\mathbf{x}$ & $\mathbf{x}$ \\
\hline \multicolumn{7}{|c|}{ Parity $i$ by 30 months } \\
\hline M-P1 & 0.94 & 0.92 & 0.97 & 0.97 & $\mathbf{x}$ & $\mathbf{x}$ \\
\hline P2 & 0.69 & 0.59 & 0.61 & 0.74 & $\mathbf{x}$ & $\mathbf{x}$ \\
\hline P3 & 0.71 & 0.62 & 0.78 & 0.70 & $\mathbf{x}$ & $\mathbf{x}$ \\
\hline P4 & 0.65 & 0.64 & 0.77 & 0.69 & $\mathbf{x}$ & $\mathbf{x}$ \\
\hline P5 & 0.67 & 0.59 & 0.75 & 0.57 & $\mathbf{x}$ & $\mathbf{x}$ \\
\hline P6 & 0.61 & 0.51 & 0.62 & 0.50 & $\mathrm{x}$ & $x$ \\
\hline M-P1 pregnant & 0.38 & 0.52 & 0.61 & 0.71 & 0.71 & 0.72 \\
\hline
\end{tabular}

Table 9 presents the cumulative proportion who, having achieved parity $i$, reach $i+1$ by 24 and by 30 months. Unlike Table 6 , this table shows interesting differentials. The New Zealand-resident oldest cohort shows generally patterns of longer spacing, in particular up to 30 months, at almost every parity progression. The middle cohort demonstrates the mixed pattern, with the New Zealand women having more rapid progressions at lower parities, but longer at higher parities. Thus, the proportions who have achieved lower parities by 24 months and by 30 months is higher for New Zealand women, whereas at higher parities this proportion falls below that for Tokelau women. Table 9 also presents data by cohort on the proportion who were pregnant at marriage. For all cohorts the proportion is higher for the New Zealand women than for the Tokelau women (c.f. Stanhope \& Prior, 1977).

\section{Discussion}

The data upon which this study is based were constructed primarily from maternity histories collected by anthropologists in the course of informal interviews conducted in Tokelauan. These were extensively supplemented by medical survey and census data, as well as available registration and baptismal records. The several sources allowed cross-checking and the identification of inconsistencies, 
which were resolved either through internal evidence or by further inquiry and the information may be viewed with confidence. It is rare in a Third World context to have data which can, on the one hand, be subject to sophisticated quantitative analysis and yet, on the other hand, permit both verification and explanatory power through an adaptation of anthropological techniques of prolonged field work and detailed knowledge of the respondent population. The adoption of life-table methods permits these data to be analysed demographically in terms of pregnancy interval dynamics by cohort and by domicile. In turn, this allows examination of the effects of longer term social change on reproduction and particularly on a fertility transition, and of the effect of large scale migration on the total society.

The cohort analysis for the entire population demonstrates that changes in pregnancy spacing and in the tempo of reproduction could permit an increase in fertility levels in what was already a population with high levels of natural fertility. Tables 6 and 7 support this finding, showing that even for the Tokelau resident population an increase in tempo accompanied by shorter spacing between pregnancies had taken place between the older (1927-41) and younger (1942-51) cohorts. Although a qualification relating to the effect of truncation biases on the younger cohorts at higher parities must be entertained, this may not be as significant as it seems. At the very least, for Tokelau residents higher parity durations do not increase while the duration between marriage and parity 1 , a result which will not be affected severely by truncation biases, shortens very considerably.

For the survey population, and even for the Tokelau resident component, these results point to the significance of changing patterns of social control on strategies of family building. A diminution in the power of social control could have affected the natural fertility components of the population in three ways. First, fewer and fewer women would marry at very early ages. Secondly, in contrast, there would be a growing increase in the probabilities of ex-nuptial conception. Finally, there would be a decrease in inter-pregnancy intervals coupled with an acceleration in tempo (cf. Harbison \& Weishaar, 1981), both of which would come from a decrease in the duration of post-partum abstention and lactation, in turn resulting from a decline in the power of post-partum taboos (Hooper \& Huntsman, 1973).

An alternative explanation might have been the effects of biosocial factors such as amenorrhoea induced by inadequate diet. This, however, is not supported by historical and contemporary evidence. Visitors throughout this century comment that the Tokelau people are well fed and healthy, and more recent dietary studies support these observations (Davidson, 1975; Harding, 1975).

Migration has added a further dimension to the changing patterns. While the migration process has further decreased the effects of social control on patterns of reproduction, the New Zealand resident women appear as innovators of new methods of control. It is among this population that birth limitation appears to be occurring at higher parities, and even, possibly, for the youngest women at the first progression between marriage and parity 1 . But migration has acted in different ways for different cohorts. The older migrants, the birth cohorts of 1927-41, had delayed pregnancies for every parity. By comparison, in more recent cohorts, (1942-51), family formation was accelerated in the lower parities, but, through increasing use of limitation, family building had decelerated at higher parities. 


\section{Acknowledgments}

We acknowledge the help of Dr H. Léridon, Institut d'Etudes Démographiques, Paris, who commented on a draft of the paper, and Ms R. Rees who coded the data. The Medical Research Council of New Zealand, Wellington Hospital Board, the Cardiovascular Division of WHO, the Auckland University Research Committee and the Wenner-Gren Foundation for Anthropological Research, supported the collection and analysis of the data. We acknowledge particularly the co-operation of the Tokelauan communities.

\section{References}

Coulibaly, S. \& Pool, I. (1975) Un essai d'explication des variations de la fécondite en Haute-Volta et au Ghana. Population et Famille, 34, 1.

Davidson, F. (1975) The Tokelau Island Migrant Study: atoll diet. In: Migration and Health in New Zealand and the Pacific, pp. 109-112. Edited by J. M. Stanhope. Wellington Postgraduate Medical Society, New Zealand.

GoldsteIN, S. (1978) Migration and fertility in Thailand 1960-70. Can. Stud. Popul. 5, 167.

HARbison, S.F. \& WEISHAAR, M.E. (1981) Samoan migrant fertility: adaptation and selection. Hum. Organ. 40, 268.

HARDING, W. (1975) The diet of Tokelau Island migrants in New Zealand. In: Migration and Health in New Zealand and the Pacific, pp. 113-116. Edited by J. M. Stanhope. Wellington Postgraduate Medical Society, New Zealand.

HobCraft, J.N. \& Rodriguez, G. (1980) Methodological Issues in Life Table Analysis of Birth Histories. World Fertility Survey, London.

Hooper, A. \& Huntsman, J. (1973) A demographic history of the Tokelau Islands. J. Polynesian Soc. 82, 366.

Nuнuis, J.M. (1983) The Family Building Process in Java: Birth Interval Analysis from the Indonesia Fertility Survey 1976. Demographic Reports 6, Groningen State University Geographical Institute, Netherlands.

PotTER, R.G. \& Kobrin, F.E. (1982) Effects of cyclic spouse separation on conception times. Math. Biosci. 59, 207.

SCEATS, J.E. (1981) Family formation in New Zealand: an analysis of the timing and spacing of pregnancies. N.Z. Popul. Rev. 7, 29.

ScEats-Pool, J. (1978) Family building in a Canadian city: an analysis of the timing and spacing of pregnancies. Popul. Stud. 32, 583.

Stanhope, J.M. \& Prior, I.A.M. (1977) The Tokelau Island Migrant Study: fertility and associated factors before migration. J. biosoc. Sci. 9, 1.

VAN De Walle, F. (1975) Migration and fertility in Ticino. Popul. Stud. 29, 447.

ZARATE, A. \& ZARATE, A.U. (1975) On the reconciliation of research findings of migrantnonmigrant fertility differentials. Int. migr. Rev. 9, 115. 